\title{
CARACTERIZAÇÃO DAS ÁREAS DE CULTIVO DA BANANEIRA 'MAÇÃ' NA REGIÃOO DE RIBEIRÃO DO SUL/SP
}

\author{
The characterization of banana 'Maçã' orchards in the Ribeirão do Sul/SP
}

\author{
Sarita Leonel ${ }^{1}$, Erval Rafael Damatto Junior ${ }^{2}$
}

\begin{abstract}
RESUMO
Objetivou-se com este trabalho caracterizar os produtores de bananeira 'Maçã' do município de Ribeirão do Sul/SP, quanto à tecnologia empregada no cultivo da frutífera e à produção obtida. A partir desta avaliação preliminar, pretendeu-se estabelecer algumas inferências com relação à incidência da doença "Mal-do-Panamá" e o diagnóstico nutricional das propriedades. Através dos questionários aplicados, bem como das análises foliares e de solo, detectou-se que os produtores realizam a prática da adubação e calagem sem resultados de análise de solo, não realizam análises foliares e que os teores de nutrientes no solo e nas folhas apresentam-se em níveis desbalanceados para muitas propriedades avaliadas. A incidência da doença "Mal-do-Panamá" foi considerada baixa ou ausente em $65 \%$ das propriedades avaliadas.
\end{abstract}

Termos para indexação: Musa sp., banana, nutrição mineral, fertilidade do solo, fitopatologia.

\section{ABSTRACT}

The research aimed to characterize banana 'Maçã' farmers of Ribeirão do Sul/SP region, regarding the technology applied to the crop and in the fruit yield. With the answers obtained, it was possible to establish some inferences in relation to the "Mal -doPanamá disease incidence and the mineral nutrition. It was observed that these farmers used manurig and liming without the use of the soil analyses and that they had never performed foliar analyses. Consequently, soil and leaves nutrients levels were not balanced for most of the evaluated plantation. The "Mal-do-Panamá" disease incidence was considered low or not present in $65 \%$ of the studied orchards.

Index terms: Musa sp., banana, mineral nutrition, soil fertility, phytopathology.

(Recebido em 27 de junho de 2006 e aprovado em 22 de fevereiro de 2007)

\section{INTRODUÇÃO}

O cultivo da bananeira é explorado na maioria dos países tropicais, sendo que em 2004 a produção mundial atingiu 70,6 milhões de toneladas, destacando-se o Brasil como segundo país produtor, com uma produção de aproximadamente 6,6 milhões de toneladas anuais e também, como maior consumidor, sendo responsável pelo consumo de aproximadamente 7,1 milhões de toneladas (AGRIANUAL, 2006).

A banana é considerada a fruta tropical de maior importância para o país, uma vez que mobiliza grande contingente de mão-de-obra, apresenta um fluxo contínuo de produção a partir do primeiro ano, o que a torna atraente para os agricultores, movimenta um número apreciável de insumos, além de ser a fruta mais consumida pelos brasileiros, que consomem aproximadamente $20 \mathrm{~kg} / \mathrm{hab} /$ ano, de acordo com Cordeiro (1988). Embora o Brasil figure como um grande produtor e consumidor de bananas, a bananicultura nacional enfrenta sérios problemas nas fases de produção e pós-colheita, que limitam a sua inserção no mercado internacional. Um dos fatores de perda é a qualidade fitossanitária da fruta. Sabe-se que somente frutos de alta qualidade, produzidos livres de pragas, doenças e distúrbios diversos são capazes de conquistar novos mercados.

De modo geral, no Brasil é possível caracterizá-la como uma cultura de baixa produtividade, baixo nível tecnológico e de elevadas perdas na pré e pós-colheita, e somente na fase de pós-colheita as perdas podem chegar a 40\% da produção (CORDEIRO, 1988). O Estado de São Paulo, considerando-se a safra de 2005 , participa com pouco mais de $16 \%$ da produção total do país, numa área de 52.700 hectares, com uma produtividade média de $21 \mathrm{t} / \mathrm{ha}$ (AGRIANUAL, 2006). Historicamente, a tradicional região produtora de bananas do Litoral Paulista é responsável pela maior parte da produção do Estado. No entanto, constata-se o crescente interesse dessa cultura por produtores do Planalto Paulista e de outras regiões, não tradicionais em seu cultivo, como forma de diversificação de atividades, como é o caso de Ribeirão do Sul/SP, onde o cultivo da bananeira 'Maçã' tem se mostrado bastante promissor e lucrativo.

\footnotetext{
Doutora, Professora Adjunto - Departamento de Produção Vegetal/DPV - Faculdade de Ciências Agronômicas/FCA - Universidade Estadual Paulista/UNESP - Rua José Barbosa de Barros, 1780 - 18610-307 - Botucatu, SP - sarinel@fca.unesp.br

2Doutorando - Departamento de Produção Vegetal/DPV - Faculdade de Ciências Agronômicas/FCA - Universidade Estadual Paulista/UNESP Rua José Barbosa de Barros, 1780 - 18610-307 - Botucatu, SP - ervaljr@fca.unesp.br - Bolsista Fapesp
} 
O interesse pelo cultivo da bananeira 'Maçã', na região de Ribeirão do Sul/SP, tem sofrido um crescente aumento devido aos bons preços pagos ao produto, isto porque nas principais regiões produtoras de banana ocorre uma doença fúngica que inviabiliza e impossibilita o cultivo da banana 'Maçã' por vários ciclos, que é o Mal-doPanamá (Fusarium oxysporum f. sp. cubense). Nessa região, os produtores têm conseguido conviver com a doença, apresenta-se de forma menos agressiva. Para a região, a produção de banana 'Maçã' pode ser uma alternativa bastante lucrativa de diversificação das atividades da propriedade, onde esses produtores não têm como fonte de renda uma única cultura.

Assim, adequar técnicas de cultivo às novas necessidades da cultura, aumentar a produtividade, atingindo valores acima de 30 t/ha, para a cultivar Maçã, diminuir perdas em todo o processo produtivo e de comercialização e, principalmente, melhorar a qualidade final do produto, com conseqüente estímulo ao consumo, são objetivos a serem conquistados pelos bananicultores da região.

A bananeira é uma planta muito exigente em nutrientes, principalmente potássio e nitrogênio, no entanto, ocorrem diferenças entre cultivares nas quantidades absorvidas, até mesmo dentro de um mesmo grupo genômico, em razão, principalmente, das características da cultivar, dos teores de nutrientes no solo e do manejo adotado (BORGES et al., 1999). Além disso, a banana é uma das culturas que extraem grandes quantidades de nutrientes por hectare, por isso uma adubação bem realizada é um dos fatores que mais influencia a produção, bem como sua qualidade e resistência à doenças (CARVALHO et al., 1986).

Conduziu-se este estudo para fornecer aos produtores de bananeira 'Maçã' na região de Ribeirão do Sul/SP, com relação à tecnologia empregada no cultivo, bem como em relação às principais dificuldades encontradas para se obter incrementos em produção. A partir daí foi diagnosticado que os dois principais problemas enfrentados pelos produtores eram o uso de fertilizantes e corretivos sem recomendações técnicas, alicerçadas sem resultados de análises químicas de solo e planta e o outro problema era a convivência com a doença "Mal-do-Panamá" (Fusarium oxysporum f. sp. cubense). Definiu-se o segundo objetivo do trabalho que foi o de estabelecer algumas comparações das propriedades avaliadas, quanto aos seus aspectos fitossanitários, avaliando a incidência da doença "Mal-do Panamá" e seus aspectos nutricionais, avaliando também o teor de nutrientes no solo e nas folhas.

\section{MATERIAL E MÉTODOS}

Coleta de dados: Foram coletados dados sobre a cultura junto à Casa da Agricultura de Ribeirão do Sul e no SEBRAE de Ourinhos, além de questionários aplicados aos produtores que cultivam essa frutífera na região. Nos questionários aplicados constavam perguntas sobre a área destinada à cultura, práticas culturais realizadas, bem como época de realização, principais insumos utilizados, uso de equipamento de proteção individual, máquinas e implementos utilizados na condução da cultura, mão-deobra contratada, principal dificuldade encontrada no cultivo, além do rendimento obtido. Realizou-se o acompanhamento de um grupo de 15 produtores de bananeira 'Maçã', do município de Ribeirão do Sul/SP e de 2 produtores de municípios vizinhos (Salto Grande e Santa Cruz do Rio Pardo). Dentre os componentes do grupo, todos pertenciam à Associação de Produtores Frutivale e caracterizavam-se por exercerem atividades predominantemente familiares.

Coleta de amostras de solo: As amostras de solo foram retiradas, no mês de Janeiro/2004, da camada de 0-20 $\mathrm{cm}$ de profundidade, sendo que cada amostra representativa era constituída por 15 sub-amostras, retiradas da região de desenvolvimento das raízes, conforme metodologia descrita por Borges et al. (1999).

Coleta de amostras de folhas: $\mathrm{Na}$ ocasião da emissão da inflorescência foram retiradas amostras das folhas em bananais dos 17 produtores, para análise dos teores de nutrientes minerais. As amostras de tecidos foliares foram retiradas de duas plantas de cada produtor, para formar uma amostra composta, sendo estas amostras coletadas da $3^{\mathrm{a}}$ folha a partir do ápice. Das folhas escolhidas, coletou-se $10 \mathrm{~cm}$ da parte interna mediana do limbo foliar, eliminando-se a nervura central, conforme é preconizado pela norma internacional (MARTIN-PRÉVEL, 1984). As folhas foram lavadas e secas, em estufa a $65^{\circ} \mathrm{C}$, e encaminhadas ao Laboratório de Nutrição Mineral de Plantas do Departamento de Recursos Naturais - Ciência do Solo, onde se realizou a análises químicas das folhas, segundo metodologia descrita por Malavolta et al. (1997), analisando os teores de nitrogênio (após digestão sulfúrica empregando-se o método semi-micro Kjedahl), fósforo, potássio, cálcio, magnésio, enxofre, boro, cobre, ferro, manganês e zinco.

\section{RESULTADOS E DISCUSSÃO}

\section{Caracterização dos produtores}

Com relação à área de cultivo destinada ao plantio de bananeira, esta era praticamente homogênea entre os 
participantes, sendo destinados entre 1 a 4 ha ao cultivo. Alguns produtores dedicavam-se ao cultivo há mais de cinco anos e outros eram iniciantes. Todos se revelaram satisfeitos com os resultados econômicos conseguidos, mas demonstraram-se preocupados com problemas, principalmente de ordem fitossanitária. Através das visitas técnicas realizadas foram observadas algumas deficiências no controle de pragas, doenças e plantas daninhas, principalmente no que se refere ao uso de produtos registrados para a cultura, época e dosagens de aplicação, pulverizadores inapropriados para bananeiras, além da pouca utilização de equipamentos de proteção individual

Além disso, estava havendo uma conscientização do grupo para a utilização de um bom material de plantio, através do uso de mudas produzidas em laboratório, bem como emprego da adubação e calagem, tomando como base resultados de análise de solo e folhas, isto porque foi detectado que os mesmos faziam a adubação anual da bananeira entre os meses de outubro a março, alguns empregando dosagens acima da recomendada para o solo da propriedade, que em muitos casos era de textura argilosa e fertilidade alta. Outros empregavam a formulação 04-1408 , considerada inadequada para bananeira, e que em alguns casos, pode levar a desbalanços entre nutrientes.

$\mathrm{O}$ espaçamento adotado para plantio da bananeira 'Maçã' na região é muito variável, pois cada produtor emprega um manejo distinto em sua propriedade, porém todos trabalhavam com 3 a 8 plantas em produção por touceira, o que influenciou o espaçamento empregado, que variou de $3 \mathrm{~m}$ entre plantas $\mathrm{x} 4 \mathrm{~m}$ entre linhas a até $6 \mathrm{~m}$ entre plantas x 4 m entrelinhas. $\mathrm{O}$ sistema de cultivo adotado pela maioria (16 produtores) foi convencional e apenas um deles adotou o sistema orgânico de cultivo. A produtividade média na região era de 11,5 ton/ha/ano, representando cerca de $523 \mathrm{cx}$ de $22 \mathrm{~kg} / \mathrm{ha} /$ ano e o preço pago por caixa ao produtor, sofria variação de acordo com a sazonalidade da cultura, sendo de R\$ 7,00 a R\$ 15,00/cx, no ano de 2004.

Pela tabela 1 é possível observar que a doença foi diagnosticada em 6 dos 17 produtores, o que leva a crer que o manejo por eles empregado pode ter influenciado na baixa incidência de "Mal do Panamá", na maioria dessas propriedades.

TABELA 1 - Caracterização das 17 propriedades de bananeira 'Maçã', do município de Ribeirão do Sul/SP.

\begin{tabular}{|c|c|c|c|c|c|}
\hline Produtor & Área (ha) & $\mathbf{N}^{\circ}$ plantas & $\begin{array}{c}\text { Produção } \\
\left.\text { (cx. } 22 \text { kg.mês }^{-1}\right)\end{array}$ & $\begin{array}{c}\text { Produção } \\
\left(\text { kg.planta }^{-1}\right)\end{array}$ & $\begin{array}{c}\text { Incidência } \\
\text { da doença } \\
\text { "Mal-doPanamá" }\end{array}$ \\
\hline 1 & 1,5 & 500 & 30 & 1,32 & ausente \\
\hline 2 & 6,0 & 1200 & 100 & 1,83 & ausente \\
\hline 3 & 2,4 & 1600 & $*$ & $*$ & ausente \\
\hline 4 & 5,0 & 3000 & 200 & 1,47 & ausente \\
\hline 5 & 7,2 & 2120 & 20 & 0,20 & ausente \\
\hline 6 & 2,0 & 1180 & 20 & 0,37 & presente \\
\hline 7 & 3,5 & 1200 & 15 & 0,27 & presente \\
\hline 8 & 0,5 & 550 & 15 & 0,6 & ausente \\
\hline 9 & 3,0 & 1700 & 50 & 0,65 & ausente \\
\hline 10 & 2,2 & 800 & 60 & 1,65 & presente \\
\hline 11 & 2,2 & 1200 & $*$ & $*$ & ausente \\
\hline 12 & 2,0 & 1300 & 40 & 0,68 & presente \\
\hline 13 & 4,0 & 2400 & 140 & 1,28 & ausente \\
\hline 14 & 3,0 & 1800 & $*$ & $*$ & ausente \\
\hline 15 & 1,0 & 700 & 20 & 0,63 & presente \\
\hline 16 & 1,5 & 1000 & 30 & 0,66 & presente \\
\hline 17 & 1,0 & 700 & $*$ & $*$ & ausente \\
\hline
\end{tabular}

\footnotetext{
* plantio novo
} 
Verifica-se na Tabela 1 que os produtores que obtiveram as menores produções foram: $5<7<6<8<15<9<16<12$, com produção por planta de 0,20 ; 0,$27 ; 0,37 ; 0,60 ; 0,63 ; 0,65 ; 0,66 ; 0,68 \mathrm{~kg} \cdot$ planta $^{-1}$, respectivamente. Nas propriedades onde se observaram as menores produções nem sempre ocorreu doença, como foi o caso dos produtores 8 e 9 , que obtiveram baixa produtividade, e as plantas não apresentaram sintomas da doença. Já o produtor 10 obteve uma boa produção por planta $\left(1,65 \mathrm{~kg}\right.$.planta $\left.{ }^{-1}\right)$ mesmo com a presença da doença no bananal.

Assim, para a maioria desses produtores, onde se observou baixa produção, verificou-se que as plantas apresentavam alguma deficiência nutricional, quer no solo ou na planta, como pode ser observado nas Tabelas 2 e 3 .

\section{Diagnose Foliar}

A análise foliar é recomendada atualmente, para aprimorar os ajustes no programa de adubação e principalmente, avaliar a necessidade de aplicação de micronutrientes. As amostras retiradas nas propriedades queriam verificar possíveis deficiências nutricionais nos bananais porque o número de plantas por touceira era elevado ( 3 a 8 plantas por touceira). Na Tabela 2 encontramse os teores médios de macro e micronutrientes em folhas de bananeira 'Maçã', das 17 propriedades caracterizadas em Ribeirão do Sul/SP.

Os teores de nitrogênio e cálcio determinados nas folhas da bananeira 'Maçã' encontravam-se segundo os padrões nutricionais conhecidos e considerados adequados (RAIJ et al., 1997), no momento do florescimento (Tabela 2); em média 29 e $6 \mathrm{~g} \mathrm{~kg}^{-1}$, respectivamente, concordando com outros autores (JONES JÚNIOR et al., 1991; PREZOTTI, 1992; ROBINSON, 1986).

Já o fósforo e o enxofre foram os nutrientes que apresentaram teores abaixo desses padrões, conforme pode ser observado na Tabela 2. Contudo esses teores estavam muito próximos ao limite inferior considerado como deficiente, e as plantas não apresentaram sintomas visuais de deficiência, para esses nutrientes.

TABELA 2 - Teores médios de macro e micronutrientes encontrados em folhas de bananeira 'Maçã', coletadas nas propriedades do município de Ribeirão do Sul, SP (Maio/2005).

\begin{tabular}{|c|c|c|c|c|c|c|c|c|c|c|c|}
\hline Produtor & $\mathbf{N}$ & $\mathbf{P}$ & $\begin{array}{l}\mathbf{K} \\
\mathbf{g} \mathbf{k g}^{-1}\end{array}$ & $\mathrm{Ca}$ & $\mathrm{Mg}$ & $\mathbf{S}$ & B & $\mathrm{Cu}$ & $\begin{array}{c}\mathrm{Fe} \\
\mathrm{mg} \mathrm{kg}^{-1}\end{array}$ & Mn & $\mathbf{Z n}$ \\
\hline 1 & 30 & 1,6 & 18 & 7 & 3,4 & 2,1 & 21 & 9 & 131 & 632 & 14 \\
\hline 2 & 28 & 1,7 & 22 & 6 & 2,9 & 2,1 & 19 & 7 & 226 & 506 & 14 \\
\hline 3 & 30 & 1,1 & 15 & 6 & 3,1 & 2,3 & 20 & 7 & 143 & 537 & 13 \\
\hline 4 & 31 & 1,5 & 22 & 6 & 3,2 & 2,0 & 20 & 8 & 237 & 975 & 14 \\
\hline 5 & 27 & 1,7 & 21 & 6 & 3,2 & 2,3 & 17 & 8 & 239 & 1465 & 13 \\
\hline 6 & 30 & 1,6 & 23 & 5 & 2,8 & 2,2 & 21 & 7 & 180 & 870 & 16 \\
\hline 7 & 28 & 1,6 & 28 & 6 & 2,9 & 2,0 & 19 & 8 & 204 & 940 & 13 \\
\hline 8 & 30 & 1,6 & 27 & 5 & 2,7 & 1,7 & 18 & 10 & 130 & 589 & 13 \\
\hline 9 & 27 & 1,6 & 29 & 4 & 2,7 & 1,8 & 22 & 9 & 144 & 390 & 15 \\
\hline 10 & 30 & 1,7 & 25 & 6 & 3,7 & 1,6 & 24 & 8 & 186 & 785 & 14 \\
\hline 11 & 28 & 1,4 & 17 & 6 & 3,4 & 1,9 & 19 & 9 & 267 & 680 & 14 \\
\hline 12 & 30 & 1,5 & 27 & 5 & 2,5 & 1,7 & 19 & 8 & 151 & 625 & 13 \\
\hline 13 & 30 & 1,6 & 23 & 6 & 2,9 & 1,8 & 17 & 8 & 213 & 1055 & 14 \\
\hline 14 & 29 & 1,6 & 29 & 5 & 3,0 & 1,6 & 19 & 8 & 167 & 530 & 13 \\
\hline 15 & 30 & 1,0 & 17 & 7 & 3,2 & 2,2 & 18 & 6 & 158 & 1160 & 13 \\
\hline 16 & 30 & 1,2 & 19 & 6 & 2,8 & 2,0 & 17 & 6 & 250 & 955 & 14 \\
\hline 17 & 30 & 1,4 & 22 & 6 & 3,0 & 1,7 & 19 & 9 & 190 & 780 & 15 \\
\hline Médias & 29 & 1,5 & 23 & 6 & 3,0 & 1,9 & 19 & 8 & 189 & 793 & 14 \\
\hline Padrão* & $27-36$ & $1,8-2,7$ & $35-54$ & $3-12$ & $3-6$ & $2,5-8,0$ & $10-25$ & $6-30$ & $80-360$ & $200-2000$ & $20-50$ \\
\hline
\end{tabular}

* Fonte: Raij et al. (1997) - Boletim Técnico 100. 
TABELA 3 - Teores médios de macronutrientes e valores médios de pH, M.O., SB, CTC e V\% de solo das propriedades de bananeira 'Maçã', do município de Ribeirão do Sul, SP (Maio/2005).

\begin{tabular}{|c|c|c|c|c|c|c|c|c|c|}
\hline Produtor & $\underset{\mathrm{pH}}{\mathrm{paCl}}$ & $\begin{array}{l}\text { M.O. } \\
\text { g/dm }\end{array}$ & $\begin{array}{c}P \\
\mathrm{mg} / \mathrm{dm}^{3}\end{array}$ & $\mathbf{K}$ & Ca & $\begin{array}{c}\mathrm{Mg} \\
\mathrm{mmol}_{\mathrm{c}} / \mathrm{dm}^{3}\end{array}$ & SB & CTC & $\begin{array}{l}\text { V\% } \\
\text { (\%) }\end{array}$ \\
\hline 1 & 5,8 & 32 & 12 & 2,0 & 78 & 20 & 100 & 126 & 80 \\
\hline 2 & 5,3 & 30 & 50 & 2,6 & 68 & 25 & 96 & 127 & 76 \\
\hline 3 & 4,8 & 27 & 32 & 2,6 & 31 & 15 & 49 & 96 & 51 \\
\hline 4 & 6,9 & 39 & 22 & 6,5 & 170 & 38 & 215 & 230 & 93 \\
\hline 5 & 4,9 & 34 & 8 & 3,0 & 64 & 24 & 91 & 133 & 68 \\
\hline 6 & 4,4 & 18 & 3 & 2,5 & 26 & 10 & 39 & 91 & 43 \\
\hline 7 & 5,6 & 24 & 19 & 3,0 & 48 & 21 & 72 & 97 & 74 \\
\hline 8 & 4,4 & 13 & 5 & 2,1 & 18 & 7 & 27 & 61 & 45 \\
\hline 9 & 4,9 & 32 & 7 & 2,2 & 45 & 19 & 66 & 113 & 58 \\
\hline 10 & 4,7 & 27 & 19 & 3,3 & 53 & 16 & 72 & 130 & 56 \\
\hline 11 & 4,8 & 39 & 15 & 4,8 & 64 & 27 & 96 & 148 & 65 \\
\hline 12 & 5,1 & 44 & 13 & 8,6 & 63 & 31 & 103 & 145 & 71 \\
\hline 13 & 5,5 & 25 & 28 & 4,2 & 62 & 22 & 89 & 120 & 74 \\
\hline 14 & 5,2 & 44 & 14 & 4,3 & 82 & 36 & 122 & 164 & 74 \\
\hline 15 & 5,4 & 20 & 25 & 2,1 & 43 & 13 & 58 & 86 & 67 \\
\hline 16 & 4,8 & 27 & 9 & 1,3 & 26 & 13 & 40 & 87 & 46 \\
\hline 17 & 5,5 & 22 & 57 & 2,2 & 66 & 14 & 82 & 110 & 75 \\
\hline Médias & 5,2 & 29 & 20 & 3,4 & 59 & 21 & 83 & 121 & 66 \\
\hline
\end{tabular}

Os teores de potássio nas folhas no momento do florescimento foram em média de $23 \mathrm{~g} \mathrm{~kg}^{-1}$, abaixo do qual é sugerido por Raij et al. (1997), porém em nenhum momento foram observados sintomas de deficiência desse nutriente nos bananais avaliados. Diversos autores relataram situações semelhantes, nos quais os teores de K estavam abaixo dos teores tidos como padrão para a cultura, sem contudo, haver sintomas visuais de deficiência do elemento. Nesse sentido, Gomes (2004) encontrou teores médios de $27 \mathrm{~g} \mathrm{~kg}^{-1}$ de potássio nas folhas, com produção de $17 \mathrm{t} \mathrm{ha}^{-1}$ para a bananeira 'Prata-anã', considerado um bom valor de produtividade para este cultivar, no primeiro ciclo. Guerra (2001) trabalhando com fertirrigação em bananeira 'Prata-anã' notou que os teores foliares de potássio estavam abaixo dos níveis adequados para a bananeira. Resultados semelhantes foram encontrados por Teixeira (2000); em um mesmo tipo de solo e sob irrigação. Damatto Junior (2005) também verificou teores de $\mathrm{K}$ abaixo do padrão (31 g de $\mathrm{K} \mathrm{kg}^{-1}$ ), em bananeira 'Prata-Anã', sem observar sintomas de deficiência de potássio nas plantas e nem queda em produtividade.

Os teores foliares de magnésio, no momento do florescimento, apresentaram-se adequados na maioria dos plantios (9 produtores), contudo em 8 bananais os teores deste nutriente encontravam-se pouco abaixo dos padrões recomendados como adequados para este nutriente, que é de 3 a $6 \mathrm{~g} \mathrm{~kg}^{-1}$.

De maneira geral, os bananais não apresentaram sintomas de deficiência em micronutrientes, com teores foliares desses nutrientes encontrados dentro da faixa adequada para a cultura. Exceção fez-se ao zinco que apresentou teores inferiores ao padrão citado por Prezotti (1992) (Tabela 2). Contudo, foram observados sintomas visuais da deficiência de zinco em apenas uma propriedade.

\section{Teores de nutrientes no solo}

Da mesma maneira que o reportado para os teores de elementos minerais presentes nas folhas, o programa 
de adubação para o Estado de São Paulo tem como base a interpretação de análise de solos para bananeiras, do subgrupo Cavendish. Importante reportar que neste subgrupo os produtores adotam o sistema de manejo com 3 plantas por touceira ou família. Diferentemente, os produtores de banana 'Maçã' adotam em média de 5 a 6 plantas por touceira, visando a não intervenção com ferramentas na área próxima ao sistema radicular das plantas, as quais poderiam estar causando ferimentos que serviriam como porta de entrada para o agente causal do "Mal-do-Panamá". Com isso, levantam-se alguns questionamentos sobre a viabilidade dessa recomendação para a bananeira 'Maçã'. Na ausência de dados para esta cultivar são feitas comparações com o recomendado por Raij et al. (1997) - Boletim 100 para a cultivar Nanica. Na Tabela 3 encontram-se os teores médios de macronutrientes e valores médios de pH, M.O., SB, CTC e V\% de solo das 17 propriedades de bananeira 'Maçã' estudadas.

Para garantir boas produções, a bananeira requer uma quantidade grande de nutrientes minerais e adubo orgânico durante o seu ciclo. De todos os nutrientes minerais, o potássio é o mais extraído e exportado pelos frutos. Sua baixa disponibilidade reduz o florescimento, aumenta o tempo de maturação dos cachos, diminui o número, o tamanho e o peso dos frutos. Deficiência de nitrogênio resulta em menor área foliar com efeitos sobre o ciclo vegetativo e a qualidade dos frutos.

Diante dos resultados apresentados na Tabela 3, pode verificar-se que os valores médios de $\mathrm{pH}$ estão numa faixa considerada média $(5,1$ a 5,5$)$, sendo que houve variação entre os 17 solos analisados.

O teor médio de fósforo no solo $\left(20 \mathrm{mg} / \mathrm{dm}^{3}\right)$ encontrava-se dentro de uma faixa considerada como média, contudo em 6 propriedades, os teores encontravam-se com valores considerados baixos, em outras 6 considerados médios e em 5 altos. Mesmo o $\mathrm{P}$ sendo um nutriente requerido em baixa quantidade pela bananeira é preciso manter seus teores no solo dentro da faixa adequada para que a produtividade seja maximizada, uma vez que $50 \%$ do fósforo absorvido pela planta é exportado pelos frutos, o que ao longo dos ciclos pode gerar deficiência deste elemento, afetando o crescimento vegetativo e também diminuindo o desenvolvimento de raízes (BORGES \& OLIVEIRA, 2000).

Nos solos analisados, o teor de potássio foi considerado alto, e esta tendência foi repetida em 4 propriedades. A maior parte das propriedades apresentava solos com teores de potássio médios (10 propriedades) e o solo de duas propriedades tinha teores de potássio muito altos, e em apenas uma o teor de potássio foi considerado baixo. Isso evidencia a preocupação e conhecimento dos produtores com relação à grande exigência de potássio pela bananeira, que corresponde a aproximadamente $41 \%$ do total de nutrientes na planta (BORGES \& OLIVEIRA, 2000).

A saturação em bases (V\%) mostrou-se em níveis abaixo do recomendado para a cultura da bananeira $(\mathrm{V} \%=$ $60 \%$ ), nos produtores $3,6,8,9,10$ e 16 , como pode ser observado na Tabela 3. Para os produtores 9 e 10, não seria recomendada a calagem na próxima safra, pois os valores da V\%, para estes dois produtores, estavam muito próximos do ideal.

Com relação aos micronutrientes, não houve sintomas visuais de deficiências ou fitotoxidez, sendo que os teores médios de manganês e cobre encontravam-se altos em todas as áreas produtoras. Os teores médios de boro no solo apresentavam-se baixos em 6 propriedades, médios em 10 e altos em apenas uma das propriedades avaliadas (Tabela 4).

Os teores médios de ferro e zinco mostraram-se altos nos solos analisados da maioria das propriedades (14 propriedades), como pode ser observado na Tabela 4. Malburg et al. (1992) relataram a importância do zinco para bananas 'Enxerto' (Prata-anã), indicando que, neste cultivar, um dos fatores que favoreceu a incidência do 'Mal-doPanamá' foi a carência de zinco no solo e, conseqüentemente, na planta.

De acordo com o relato de Simmonds (1959), por ser o agente causador do “'Mal-do-Panamá” um fungo de solo, são evidentes as interferências das condições do solo no desenvolvimento da doença. Cordeiro (1988) fazendo uma compilação sobre o assunto, destacou algumas características do solo e como elas podem se correlacionar com o desenvolvimento da doença. Tomando como base esse estudo, foram levantadas algumas premissas como a de que plantas cultivadas em solos com maiores níveis de $\mathrm{pH}$, cálcio, magnésio, zinco e matéria orgânica estão menos sujeitos à infecção por $F$. oxysporum $f$. sp. cubense e que qualquer estresse, sofrido pela planta, interfere diretamente no seu mecanismo de resistência.

Seguindo essa linha de raciocínio, muitos técnicos recomendam e alguns produtores adotam técnicas de manejo como calagem e adubação, uso de matéria orgânica em grande quantidade e o uso de práticas culturais empregando-se o mínimo de ferramentas que provoquem ferimentos nas plantas, visando o manejo cultural da doença.

Porém, durante a realização deste trabalho, tais premissas não puderam ser comprovadas na prática, uma vez que não foi possível estabelecer comparações entre 
TABELA 4 - Teores médios de micronutrientes de solo em áreas produtorss de bananeira 'Maçã', do município de Ribeirão do Sul, SP (Maio/2005).

\begin{tabular}{cccccc}
\hline Produtor & Ferro & Manganês & Cobre & Zinco & Boro \\
\hline 1 & 10 & 50,8 & 7,8 & 1,0 & 0,16 \\
2 & 18 & 40,2 & 20,6 & 4,6 & 0,61 \\
3 & 14 & 49,2 & 8,6 & 0,7 & 0,43 \\
4 & 7 & 21,2 & 7,9 & 2,4 & 0,10 \\
5 & 33 & 129,0 & 12,0 & 1,8 & 0,13 \\
6 & 18 & 30,0 & 6,0 & 1,6 & 0,29 \\
7 & 11 & 27,6 & 6,3 & 1,0 & 0,07 \\
8 & 44 & 95,5 & 4,8 & 1,7 & 0,23 \\
9 & 18 & 74,6 & 20,8 & 1,4 & 0,18 \\
10 & 14 & 59,8 & 8,0 & 2,3 & 0,24 \\
11 & 20 & 70,6 & 26,4 & 1,9 & 0,28 \\
12 & 74 & 64,0 & 6,2 & 8,1 & 0,39 \\
13 & 15 & 50,8 & 18,8 & 2,5 & 0,38 \\
14 & 37 & 52,4 & 14,3 & 5,0 & 0,31 \\
15 & 13 & 15,2 & 3,4 & 1,8 & 0,32 \\
16 & 17 & 8,5 & 4,5 & 1,3 & 0,19 \\
17 & 13 & 13,4 & 4,3 & 1,9 & 0,26 \\
\hline Média & 22 & 50,2 & 10,6 & 2,4 & 0,27 \\
\hline
\end{tabular}

propriedades com solo e plantas que apresentavam níveis nutricionais considerados adequados, dentro dos padrões estabelecidos para bananeiras de um modo geral, com a incidência da doença "Mal-do-Panamá”. A única constatação que foi possível relatar é que, nas áreas que apresentavam a incidência da doença, a produção obtida era menor quando comparada com as propriedades em que não havia a ocorrência do "Mal-do-Panamá", o que já era esperado.

\section{CONCLUSÕES}

$\mathrm{Na}$ caracterização das propriedades que cultivam bananeira 'Maçã' em Ribeirão do Sul/SP detectou-se que os produtores realizavam a prática da adubação e calagem sem resultados de análise de solo, nunca haviam realizado análises foliares e com isso, os teores de nutrientes no solo e nas folhas estavam em níveis desbalanceados, para muitas propriedades avaliadas. A incidência da doença "Mal-do-Panamá" foi considerada baixa ou ausente em $65 \%$ das propriedades avaliadas.

\section{REFERÊNCIAS BIBLIOGRÁFICAS}

AGRIANUAL. Anuário estatístico da agricultura brasileira. São Paulo: FNP Consultoria \& Comércio, 2006. $504 \mathrm{p}$.

BORGES, A. L.; OLIVEIRA, A. M. G. Nutrição Calagem e Adubação. In: CORDEIRO, Z. J. M. Banana: aspectos técnicos. Brasília, DF: Embrapa Comunicação para Transferência de Tecnologia, 2000. p. 47-59. (Frutas do Brasil, 1).

BORGES, A. L.; OLIVEIRA, A. M. G.; SOUZA, L. da S. Solos, nutrição e adubação. In: ALVES, E. J. A cultura da banana: aspectos técnicos socioeconômicos e agroindustriais. Brasília, DF: Embrapa-SPI, 1999. p. 197-260.

CARVALHO, J. G. de; PAULA, M. B. de; NOGUEIRA, F. D. Nutrição e adubação da bananeira: a cultura da bananeira. Informe agropecuário, Belo Horizonte, n. 133, p. 20-32, 1986. 
CORDEIRO, Z. J. M. Inter-relaçõs entre mal-do-panmá e características químicas e físicas do solo. Revista Brasileira de Fruticultura, Cruz das Almas, v. 10, n. 1, p. 89-91, 1988.

DAMATTO JUNIOR, E. R. Efeitos da adubação com composto orgânico na fertilidade do solo, desenvolvimento, produção e qualidade de frutos de bananeira 'Prata-anã' (Musa AAB). 2005. 70 f. Dissertação (Mestrado em Agronomia/Energia na Agricultura) - Faculdade de Ciências Agronômicas, Universidade Estadual Paulista, Botucatu, 2005.

GOMES, E. M. Crescimento e produção de bananeiras 'Prata-anã' e 'Maçã' fertirrigadas com potássio. 2004. 76 f. Tese (Doutorado em Agronomia/Irrigação e Drenagem) Faculdade de Ciências Agronômicas, Universidade Estadual Paulista, Botucatu, 2004.

GUERRA, A. G. Fertirrigação com nitrogênio e potássio utilizando sistema de irrigação por microaspersão na cultura da bananeira 'Prata-anã'. 2001. 69 f. Tese (Doutorado em Agronomia/Produção Vegetal) - Faculdade de Ciências Agrária e Veterinárias, Universidade Estadual Paulista, Jaboticabal, 2001.

JONES JÚNIOR, J. B.; WOLF, B.; MILLS, H. A. Plant analyses handbook: a practical sampling, preparation, analyses and interpretation guide. Athens: Micro-Macro, 1991. $213 \mathrm{p}$.

MALAVOLTA, E.; VITTI, G. C.; OLIVEIRA, S. A. de.Avaliação do estado nutricional das plantas: princípios e aplicações. 2. ed. rev. e atual. Piracicaba: Potafos, 1997. 319 p.
MALBURG, J. L.; CARVALHO, J. G.; VALE, F. R.; GUEDES, G. A. A.; ANJOS, J. T. Amostragem foliar para a diagnose nutricional de zinco na bananeira 'Enxerto' ('Prata-anã') em Santa Catarina. Revista Brasileira de Fruticultura, Cruz das Almas, v. 14, n. 1, p. 21-26, 1992.

MARTIN-PRÉVEL, P. Bananier. In: MARTIN-PRÉVEL, P.; GAGNARD, J.; GAUTIER, P. (Eds.). L'analyse végétale dans le contrôle de l'atation des plantes tempérées et tropicales. Paris: Tec \& Doc, 1984. p. 715-751.

PREZOTTI, L. C. Recomendação de calagem e adubação para o Estado do Espírito Santo: $3^{\mathrm{a}}$ aproximação. Vitória: EMCAPA, 1992. 73 p. (Circular técnica, 12).

RAIJ, B. van; CANTARELLA, H.; QUAGGIO, J. A.; FURLANI, A. M. C. (Eds.). Recomendações de adubação e calagem para o Estado de São Paulo. 2. ed. rev. e atual. Campinas: Instituto Agronômico/Fundação IAC, 1997. 285 p. (Boletim técnico, 100).

ROBINSON, J. B. Fruits, vines e nuts. In: REUTER, D. J.; ROBINSON, J. B. (Eds.). Plant analyses: an interpretation manual. Melbourne: Inkata, 1986. p. 120-147.

SIMMONDS, N. W. Bananas. London: Longman, 1959. $466 \mathrm{p}$.

TEIXEIRA, L. A. J. Adubação nitrogenada e potássica em bananeira 'Nanicão' (Musa AAA subgrupo Cavendish) sob duas condições de irrigação. 2000. $130 \mathrm{f}$. Tese (Doutorado em Agronomia/Produção Vegetal) - Faculdade Ciências Agrária e Veterinárias, Universidade Estadual Paulista, Jaboticabal, 2000. 